\title{
HIV Treatment as Prevention and the Role of Applied Social Science Research
}

Will Small and Thomas Kerr*

Associate Professor, Department of Medicine, University of British Columbia, St. Paul's Hospital, 608-1081 Burrard Street, Vancouver, British Columbia, Canada

Utilizing highly active antiretroviral therapy (HAART) to reduce HIV transmission, commonly referred to as "treatment as prevention" (TASP), has been hailed as a valuable addition to comprehensive HIV prevention efforts [1]. Subsequent to the HPTN 052 trial [2], which established the efficacy of this approach, there have been calls to prioritize TasP within global HIV prevention efforts [3].

However, some have argued that the increasing emphasis on this form of biomedical prevention represents a "remedicalisation" of the HIV epidemic [4]. Concerns have been expressed that TasP will lead to the prioritization of biomedical solutions at the expense of other preventive approaches, detract attention from the social and material conditions that shape the epidemic, and lead to a proliferation of interventions deployed without adequate input from social scientists, community, and activists [4,5]. However, such critiques overlook growing attention to the social and structural dimensions of TasP [6], opportunities to link TasP with ongoing treatment advocacy efforts [7], as well as increasing recognition that the greatest reduction in the number of new HIV infections will be achieved by integrating biomedical, social, and structural interventions in comprehensive prevention programs [8].

Just as HIV epidemics are shaped by social and material conditions, access and adherence to HIV treatment are shaped by diverse forces within the broader social, legal, political, and economic environment $[6,9,10]$. Accordingly, rather than inherently detracting attention from social and material conditions, TasP provides ample opportunity to attend to these factors.

While critics argue that expanding biomedical prevention will marginalize social science, efforts to integrate TasP into combination HIV prevention will in fact require extensive collaboration between investigators from diverse disciplines [11], as well as high quality social research identifying how social-structural forces shape access to HAART $[5,12]$. TasP programs will focus upon individuals who are most likely to transmit HIV, and there is a need to understand precisely how policy and legal frameworks shape access to HIV care among marginalized populations, including people who use drugs, sex workers, and prisoners. Documenting the influence of social-structural forces upon HAART uptake and retention should represent a key priority within the TasP research agenda [13], so that this knowledge can be utilized in the development of social and structural interventions that will effectively facilitate uptake of treatment and address barriers to care [12]. Further, TasP should be considered within a continuum of prevention programs and implementation science should examine the additive effect of TaSP, as well as the impact of TaSP on access to and uptake of other prevention programs.

Injection drug users (IDUs) in many settings have low rates of HAART uptake, and high rates of treatment interruption and failure [14], but little attention has been devoted to examining how extraindividual forces shape treatment among IDUs [9]. IDUs can derive full benefit from HAART when adequate levels of adherence are maintained [15], but unfortunately in most settings public health systems are not adequately engaging IDUs or providing optimal HIV care [14]. In many regions where HIV is highly prevalent among IDUs, criminalization of drug use places IDUs beyond the reach of public health programs, as key prevention measures (including needle exchange \& methadone) are often not available due to legal and policy barriers $[14,16]$. In some settings IDUs are systematically denied access to HIV treatment $[14,16]$.

Even where government supported public health programs engage IDUs, law enforcement practices may have a negative impact upon TasP efforts as intense policing initiatives within drug scenes often have the perverse effect of disconnecting drug users from health programs [17]. However, it is not known how particular types of police initiatives may shape HAART access and adherence among drug users, as these questions have not yet been fully examined in relation to HIV-treatment. The impact of crackdown style policing campaigns on HIV treatment outcomes has not been evaluated to date, and it is important to recognize that policing-related forces have potential to influence HAART uptake and retention among drug users in locales around the globe. There is also a need to implement more appropriate policing practices that do not undermine public health efforts, and recommendations for re-aligning law enforcement practices include the use of enhanced police training and policing policies that officially support public health measures [14,17]. These efforts can be informed by, and undertaken in concert with, human rights activists working to address the harms of enforcement. However, the public health impacts of these measures remain unknown, and evaluating the effectof these efforts should be a key priority in the era of TasP.

Given the importance of prison systems in the spread of HIV, expansion of TasP into HIV prevention for prisoners should be a priority, but it appears that various social-structural forces heavily influence treatment outcomes among incarcerated HIV positive individuals $[18,19]$. While HAART has been successfully provided to inmates within some jurisdictions of the US correctional system [18], existing research suggests that treatment outcomes vary between settings, as incarceration has been associated with discontinuation of HAART in other locales [20]. There is a need to understand how institutional and operational features of specific correctional systems

*Corresponding author: Thomas Kerr, PhD Director, Urban Health Research Initiative, British Columbia Centre for Excellence in HIVIAID, Associate Professor, Department of Medicine, University of British Columbia, St. Paul's Hospital, 608-1081 Burrard Street, Vancouver, British Columbia,Canada, V6Z 1Y6, Tel: 604-806-9116 Fax 604-806-9044; E-mail: uhri-tk@cfenet.ubc.ca

Received November 23, 2011; Accepted November 24, 2011; Published November 28, 2011

Citation: Small W, Kerr T (2011) HIV Treatment as Prevention and the Role of Applied Social Science Research. J AIDS Clinic Res 2:102e. doi:10.4172/2155$6113.1000102 \mathrm{e}$

Copyright: ( $) 2011$ Small W, et al. This is an open-access article distributed unde the terms of the Creative Commons Attribution License, which permits unrestricted use, distribution, and reproduction in any medium, provided the original author and source are credited. 
Citation: Small W, Kerr T (2011) HIV Treatment as Prevention and the Role of Applied Social Science Research. J AIDS Clinic Res 2:102e. doi:10.4172/2155-6113.1000102e

may pose barriers to access and adherence $[19,20]$, as well as how these features vary between settings. The transition between custody and the community also merits further examination, as these transitional events appear to be particularly important in shaping treatment outcomes $[21,22]$. Social science research can generate much needed information regarding these complex forces, and help to inform structural interventions that aim to enhance HIV treatment for inmates.

Unfortunately, critiques that represent the expansion of biomedical prevention as "remedicalizing" the HIV epidemic may have the uni tended effect of resurrecting polarizing debates regarding which single response to HIV disease (i.e., treatment or prevention) is the most "effective", despite consensus that combination HIV prevention that includes HIV treatment is the key to minimizing new infections. Further, social change will also be needed if TasP is to be "effective" within HIV prevention efforts, and in bringing care and treatment to vulnerable individuals living with HIV. Integrating TASP into combination prevention provides opportunities to leverage rightsbased arguments and calls for evidence-based policy in order to promote more comprehensive responses to local epidemics. In turn, efforts to address social-structural barriers to treatment can support, and be supported by, existing advocacy campaigns undertaken by AIDS activists, including those focused on ensuring treatment access to those in need. Regardless, understanding and addressing these forces in the design of programs represents a key challenge of incorporating TasP into prevention efforts, and a unique opportunity for social science research to play a greater role in determining the response to the HIV epidemic.

\section{References}

1. Lancet Infectious Diseases (2011) Treatment as prevention for HIV. Lancet Infect Dis 11: 651

2. Cohen MS, Chen YQ, McCauley M, Gamble T, Hosseinipour MC, et al. (2011) Prevention of HIV-1 infection with early antiretroviral therapy. N Engl J Med 365: 493-505.

3. Lancet (2011) HIV treatment as prevention-it works. Lancet 377: 1719.

4. Nguyen VK, Bajos N, Dubois-Arber F, O’Malley J, Pirkle CM (2011) Remedicalizing an epidemic: from HIV treatment as prevention to HIV treatment is prevention. AIDS 25: 291-293.

5. Kippax SC, Holt M, Friedman SR (2011) Bridging the social and the biomedical: engaging the social and political sciences in HIV research. J Int AIDS Soc 14 Suppl 2: S1.

6. Kippax S, Reis E, de Wit J (2011) Two Sides to the HIV Prevention Coin Efficacy and Effectiveness. AIDS Educ Prev 23: 393-396.
7. Wolfe D, Cohen J (2010) Human rights and HIV prevention, treatment, and care for people who inject drugs: key principles and research needs. J Acquir Immune Defic Syndr 1: S56-62.

8. Merson M, Padian N, Coates TJ, Gupta GR, Bertozzi SM, et al. (2008) Combination HIV prevention. Lancet 372: 1805-1806.

9. Krüsi A, Wood E, Montaner J, Kerr T (2010) Social and structural determinants of HAART access and adherence among injection drug users. Int J Drug Policy 21: 4-9.

10. Jürgens R, Csete J, Amon JJ, Baral S, Beyrer C (2010) People who use drugs, HIV, and human rights. Lancet 376: 475-485.

11. Adam BD (2011) Epistemic fault lines in biomedical and social approaches to HIV prevention. J Int AIDS Soc 2: S2.

12. Williams B, Wood R, Dukay V, Delva W, Ginsburg D et al. (2011) Treatment as prevention: preparing the way. J Int AIDS Soc 1: S6.

13. Macqueen KM (2011) Framing the social in biomedical HIV prevention trials: a 20-year retrospective. J Int AIDS Soc 2: S3.

14. Wolfe D, Carrieri MP, Shepard D (2010) Treatment and care for injecting drug users with HIV infection: a review of barriers and ways forward. Lancet 376 355-366.

15. Wood E, Hogg RS, Lima VD, Kerr T, Yip B, et al. (2008) Highly active antiretroviral therapy and survival in HIV-infected injection drug users. JAMA 300: $550-554$

16. Strathdee SA, Hallett TB, Bobrova N, Rhodes T, Booth R, et al. (2010) HIV and risk environment for injecting drug users: the past, present, and future. Lance 376: 268-284.

17. Kerr T, Small W, Wood E (2005) Public health and social impacts of targeted enforcement in street-based illicit drug markets: A review of the evidence. International Journal of Drug Policy 16: 210-220.

18. Rich JD, Wohl DA, Beckwith CG, Spaulding AC, Lepp NE, et al. (2011). HIV Related Research in Correctional Populations: Now is the Time. Curr HIVIAIDS Rep 8: 288-296.

19. Small W, Wood E, Betteridge G, Montaner J, Kerr T (2009) The impact of incarceration upon adherence to HIV treatment among HIV-positive injection drug users: a qualitative study. AIDS Care 21: 708-714

20. Milloy MJ, Kerr T, Buxton J, Rhodes T, Guillemi S, et al. (2011) Dose-response effect of incarceration events on nonadherence to HIV antiretroviral therapy among injection drug users. J Infect Dis 203: 1215-1221.

21. Springer SA, Spaulding AC, Meyer JP, Altice FL (2011) Public health implications for adequate transitional care for HIV-infected prisoners: five essential components. Clin Infect Dis 53: 469-479.

22. Draine J, Ahuja D, Altice FL, Arriola KJ, Avery AK, et al. (2011) Strategies to enhance linkages between care for HIVIAIDS in jail and community settings. AIDS Care 23: 366-377. 